\title{
Radiation Softening and Hardening in Neutron Irradiated Molybdenum
}

\author{
By M. Tanaka*, K. Fukaya* and K. Shiraishi*
}

\begin{abstract}
Molybdenum was neutron irradiated at reactor ambient temperature in the range from $6.3 \times 10^{21}$ to $5.0 \times 10^{23} \mathrm{n} / \mathrm{m}^{2}\left(E_{n}>1 \mathrm{MeV}\right)$ and was tensile tested over a range of temperatures from 223 to $525 \mathrm{~K}$ and of strain rates from $2.8 \times 10^{-6}$ to $2.8 \times 10^{-2} / \mathrm{s}$. The radiation softening was observed in the specimen irradiated to $6.3 \times 10^{21}$ and $1.0 \times 10^{22} \mathrm{n} / \mathrm{m}^{2}$ in testing at room temperature with strain rates larger than $2.8 \times 10^{-4} / \mathrm{s}$. The softening is considered to be due to small defect clusters with strain field. The athermal component of the yield stress was increased by the neutron irradiation and further increased by post-irradiation annealing up to $780 \mathrm{~K}$. The hardening is attributable to defect clusters without strain field.
\end{abstract}

(Received April 7, 1979)

\section{Introduction}

The possibility of increased usage of molybdenum as reactor material has provided impetus for more detailed and fundamental studies of the neutron irradiation effect on its mechanical properties. Molybdenum is attractive because of its high strength at high temperature and good corrosion resistance to hydrogen and coolant materials. The molybdenum, however, in common with metals of the $B C C$ family, suffers an increase in ductilebrittle transition temperature (DBTT) by neutron irradiation. The DBTT is strain rate dependent, and the yield stress of molybdenum is greatly dependent upon test temperature as well as strain rate ${ }^{(1)}$. In the discussion on the temperature and/or strain rate dependence, the yield stress $\sigma_{y}$ is usually separated into two additive components,

$$
\sigma_{y}=\sigma^{*}+\sigma_{\mu},
$$

where an athermal component $\sigma_{\mu}$ depends on temperature through the shear modulus $\mu$ and a thermal component $\sigma^{*}$ depends on temperature and strain rate ${ }^{(2)}$.

A reduction in $\sigma^{*}$ due to neutron irradiation has been reported for molybdenum of high purity single crystal rods in a certain tem-

* Japan Atomic Energy Research Institute, Tokaimura, Ibaraki-ken 319-11, Japan. perature range ${ }^{(3)(4)}$. With neutron or electron irradiated high purity iron, the radiation softening has been discussed to result from the formation of a double kink in a screw dislocation by the aid of strain field around selfinterstitials $^{(5)(6)}$ or defect clusters ${ }^{(7)(8)}$. An increase in $\sigma^{*}$ with neutron irradiation has also been reported in iron ${ }^{(9)(10)}$ and niobium ${ }^{(11)}$. It is shown with neutron irradiated vanadium that an increase, decrease, or no change in $\sigma^{*}$ can arise depending upon interstitial impurity concentration $^{(12)}$. Neutron irradiation increases the athermal component of the yield stress, $\sigma_{\mu}$ in $B C C$ metals $^{(11) \sim(15)}$. The athermal hardening is well correlated with the density and size distribution of the defect clusters ${ }^{(16) \sim(18)}$. In addition, the radiation-produced defect clusters could be thermal or athermal obstacles depending upon their size ${ }^{(11)}$.

The paper describes the temperature and strain rate dependence of the yield stress in neutron irradiated molybdenum and discusses the radiation softening and hardening in terms of the density and size distribution of defect clusters visible with electron microscopy.

\section{Experimental Procedure}

The material used in this study was $99.95 \%$ molybdenum in the form of $0.25 \mathrm{~mm}$ thick sheet obtained from Material Research Corporation. The impurity contents analysed by the vender are listed in Table 1 . The 
Table 1 Impurity content in $99.95 \%$ molybdenum.

\begin{tabular}{llllllll} 
Element & $\mathrm{O}$ & $\mathrm{C}$ & $\mathrm{Si}$ & $\mathrm{Fe}$ & $\mathrm{Cr}$ & $\mathrm{Ni}$ & $\mathrm{W}$ \\
ppm by wt. & 30 & 25 & 20 & 30 & 15 & 20 & 20 \\
\hline
\end{tabular}

specimens for tensile testing $(5 \mathrm{~mm}$ wide and $30 \mathrm{~mm}$ gauge length) and electron microscopy were annealed for $1 \mathrm{~h}$ at $1673 \mathrm{~K}$ in a vacuum better than $1.33 \times 10^{-5} \mathrm{~Pa}$. After the heat treatment the tensile specimens had an average grain diameter of $60 \mu \mathrm{m}$ with pronounced $\{100\}$ or $\{111\}$ textures. Some specimens were irradiated at ambient temperature $(\sim 320 \mathrm{~K})$ in T-pipe of JRR-4 at Tokai-mura to fluences of $6.3 \times 10^{21}$ and $1.0 \times 10^{22} \mathrm{n} / \mathrm{m}^{2} \quad\left(E_{n}>1 \mathrm{MeV}\right)$. The other specimens were irradiated at ambient temperature $(\sim 340 \mathrm{~K})$ in VT-1 of JRR-2 to fluences of 2.4 and $5.0 \times 10^{23} \mathrm{n} / \mathrm{m}^{2} \quad\left(E_{n}>1\right.$ $\mathrm{MeV}$ ).

Tensile tests were performed with an Instron tensile testing machine at strain rates ranging from $2.8 \times 10^{-6}$ to $2.8 \times 10^{-2} / \mathrm{s}$ at temperatures in the range from 223 to $525 \mathrm{~K}$. The specimen and the specimen holder were immersed in ethanol solution chilled by dry ice for tensile testing below room temperature, and in heated silicon oil for higher temperature testing. With the specimens annealed for $1 \mathrm{~h}$ at temperatures up to $1373 \mathrm{~K}$ in the vacuum after irradiation, tensile tests were made at room temperature with a strain rate of $2.8 \times 10^{-4} / \mathrm{s}$. The yield stress was obtained from the load-elongation curves as the stress at $0.2 \%$ plastic strain. When a yield drop occurred, the upper yield stress was used for the yield stress.

The thin foils for electron microscopy observation were prepared by jet polishing at $290 \mathrm{~K}$, using solution of $30 \% \mathrm{H}_{2} \mathrm{SO}_{4}$ in methanol. The observations were made with a JEM-200A electron microscope operating at $200 \mathrm{kV}$. The foil thickness were determined by counting the number of equal thickness fringes from the specimen edge or at the grain boundary.

\section{Experimental Results}

The typical stress-strain curves obtained in the tensile tests at room temperature with a strain rate of $2.8 \times 10^{-4} / \mathrm{s}$ for irradiated and

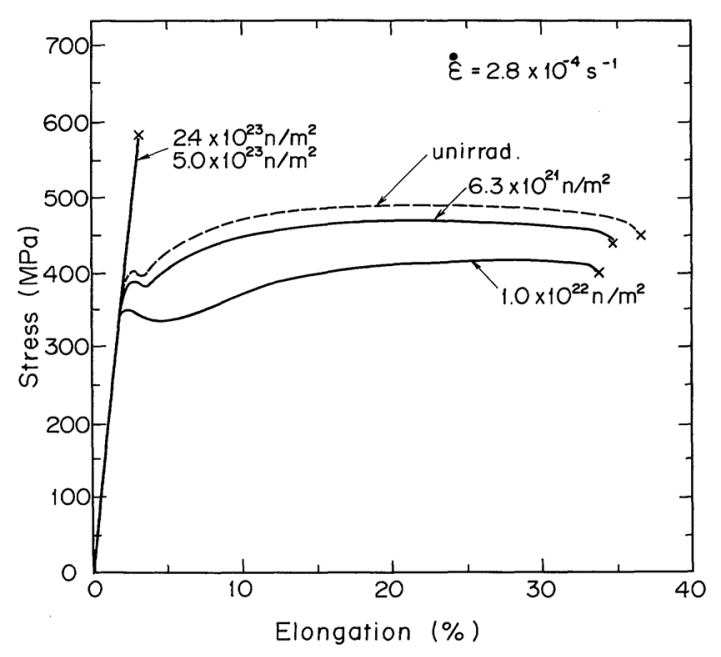

Fig. 1. Stress-strain curves at room temperature in irradiated and unirradiated molybdenum deformed with a strain rate of $2.8 \times 10^{-4} / \mathrm{s}$.

unirradiated specimens are shown in Fig. 1. The specimen irradiated to 2.4 and $5.0 \times 10^{23}$ $\mathrm{n} / \mathrm{m}^{2}$ (high fluence specimens) are fractured with little plastic deformation. The fracture stress of $579 \mathrm{MPa}$ is larger by $196 \mathrm{MPa}$ than that of the unirradiated molybdenum. On the other hand, the irradiations to $6.3 \times 10^{21}$ and $1.0 \times 10^{22} \mathrm{n} / \mathrm{m}^{2}$ (low fluence specimens) caused the decrease of the yield stress by 11 and 27 MPa from the value for the unirradiated molybdenum, respectively, i.e. radiation softening is observed in the low fluence specimens.

The magnitude of the irradiation induced change in the yield stress depends greatly upon the strain rate in the tensile tests. The yield stresses for the irradiated and unirradiated specimens tensile-tested at $300 \mathrm{~K}$ are shown in Fig. 2 as a function of the strain rate. The data for irradiated molybdenum fall on the respective single straight lines in the $\log \sigma_{y}-\log \dot{\varepsilon}$ plot, while the data for unirradiated specimen are composed of two straight lines. The slope of the line decreases with increase in neutron fluence. The lines for the samples irradiated to $6.3 \times 10^{21}$ and $1.0 \times 10^{22} \mathrm{n} / \mathrm{m}^{2}$ intersect with the line for unirradiated molybdenum. Radiation softening in the low fluence specimens occurs when the tensile test are made with high strain rates, whereas radiation hardening is observed in the same specimens when they are tested with 


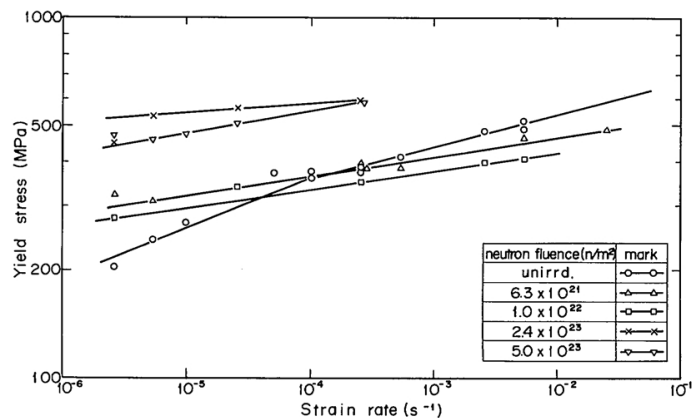

Fig. 2 Strain rate dependence of yield stress for irradiated and unirradiated molybdenum deformed at room temperature.

low strain rates. Only the irradiation hardening is observed in high fluence specimens, and the sample fractured brittle manner at the tests with strain rates higher than $2.8 \times 10^{-4} / \mathrm{s}$.

In accordance with strain rate dependence, both the hardening and softening occurred depending on test temperature in the low fluence specimens. The temperature dependence of the yield stress for the irradiated and the unirradiated molybdenum is shown in Fig. 3. The yield stress increases as lowering the test temperature until the specimens are fractured in brittle manner; unirradiated and low fluence specimens fractured brittlly below $213 \mathrm{~K}$ in the tensile testing at a strain rate of $2.8 \times 10^{-4} / \mathrm{s}$. The magnitude of radiation softening is larger in the specimen irradiated to $1.0 \times 10^{22} \mathrm{n} / \mathrm{m}^{2}$ than in the specimen irradiated to $6.7 \times 10^{21}$ $\mathrm{n} / \mathrm{m}^{2}$. The yield stress in the temperature dependence curves can be divided into two parts, the thermal component $\sigma^{*}$ and the

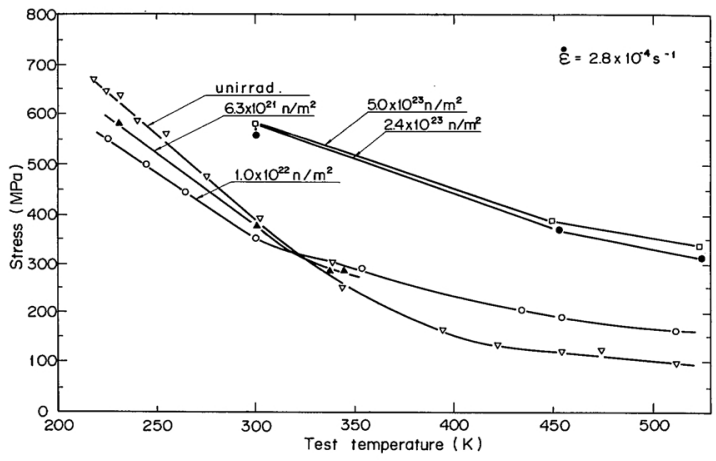

Fig. 3 Temperature dependence of yield stress for irradiated and unirradiated molybdenum deformed with a strain rate of $2.8 \times 10^{-4} / \mathrm{s}$. athermal component $\sigma_{\mu}$. In the molybdenum used in this experiment, the yield stress above $453 \mathrm{~K}$ can be referred to the athermal component. The thermal component of the yield stress at $300 \mathrm{~K}, \sigma^{*}(300 \mathrm{~K})$, is estimated with the equation, $\sigma^{*}(300 \mathrm{~K})=\sigma_{y}(300 \mathrm{~K})-\sigma_{y}(453$ $\mathrm{K})$, where $\sigma_{y}(300 \mathrm{~K})$ and $\sigma_{y}(453 \mathrm{~K})$ are the yield stresses at 300 and $453 \mathrm{~K}$, respectively. The fluence dependence of the thermal and the athermal components of the yield stress at 300 $\mathrm{K}$ is summarized in Table 2. It can be seen from the table that the thermal component is decreased by the neutron irradiations, whereas the athermal component is increased monotonously with the increase of neutron fluence. The radiation softening observed in the low fluence specimens is resulted from the fact that the decrement of the thermal component surpass the increment of the athermal component by the neutron irradiation.

The damage structure formed in molybdenum irradiated at ambient temperature is shown in Photo. 1, and size distribution of the defect clusters taken in about $0.4 \mathrm{~nm}$ intervals is presented as the histograms in Fig. 4. The data were evaluated from high contrast bright field print with the operating diffraction vector $\bar{g}=[110]$ and Bragg deviation parameter $W_{g} \approx 1.0$ on which the image of small defect clusters appears as black dots irrespective of the location in the foil. The number density of defect clusters in the specimen irradiated to $6.7 \times 10^{21} \mathrm{n} / \mathrm{m}^{2}$ was estimated to be $3.6 \times$ $10^{22} / \mathrm{m}^{3}$ in the range of size from $1.2 \mathrm{~nm}$ to $5.4 \mathrm{~nm}$, and the average diameter was $2.0 \mathrm{~nm}$. Both the number density and the average diameter of the clusters were little changed by

Table 2 Yield and thermal stress at $300 \mathrm{~K}, \sigma_{y}(300 \mathrm{~K})$ and $\sigma^{*}(300 \mathrm{~K})$, and athermal stress $\sigma_{\mu}$ in irradiated and unirradiated molybdenum.

\begin{tabular}{lccc}
\hline $\begin{array}{l}\text { Neutron } \\
\text { fluence } \\
\left(\mathrm{n} / \mathrm{m}^{2}\right)\end{array}$ & $\begin{array}{c}\sigma_{y}(300 \mathrm{~K}) \\
(\mathrm{MPa})\end{array}$ & $\begin{array}{c}\sigma^{*}(300 \mathrm{~K}) \\
(\mathrm{MPa})\end{array}$ & $\begin{array}{c}\sigma_{\mu} \\
(\mathrm{MPa})\end{array}$ \\
\hline Unirrad. & 383 & 261 & 122 \\
$6.7 \times 10^{21}$ & 372 & $176^{*}$ & $196^{*}$ \\
$1.0 \times 10^{22}$ & 356 & 160 & 196 \\
$2.4 \times 10^{23}$ & 579 & 210 & 369 \\
$5.0 \times 10^{23}$ & 579 & 200 & 379 \\
\hline \hline
\end{tabular}

* extrapolated value. 


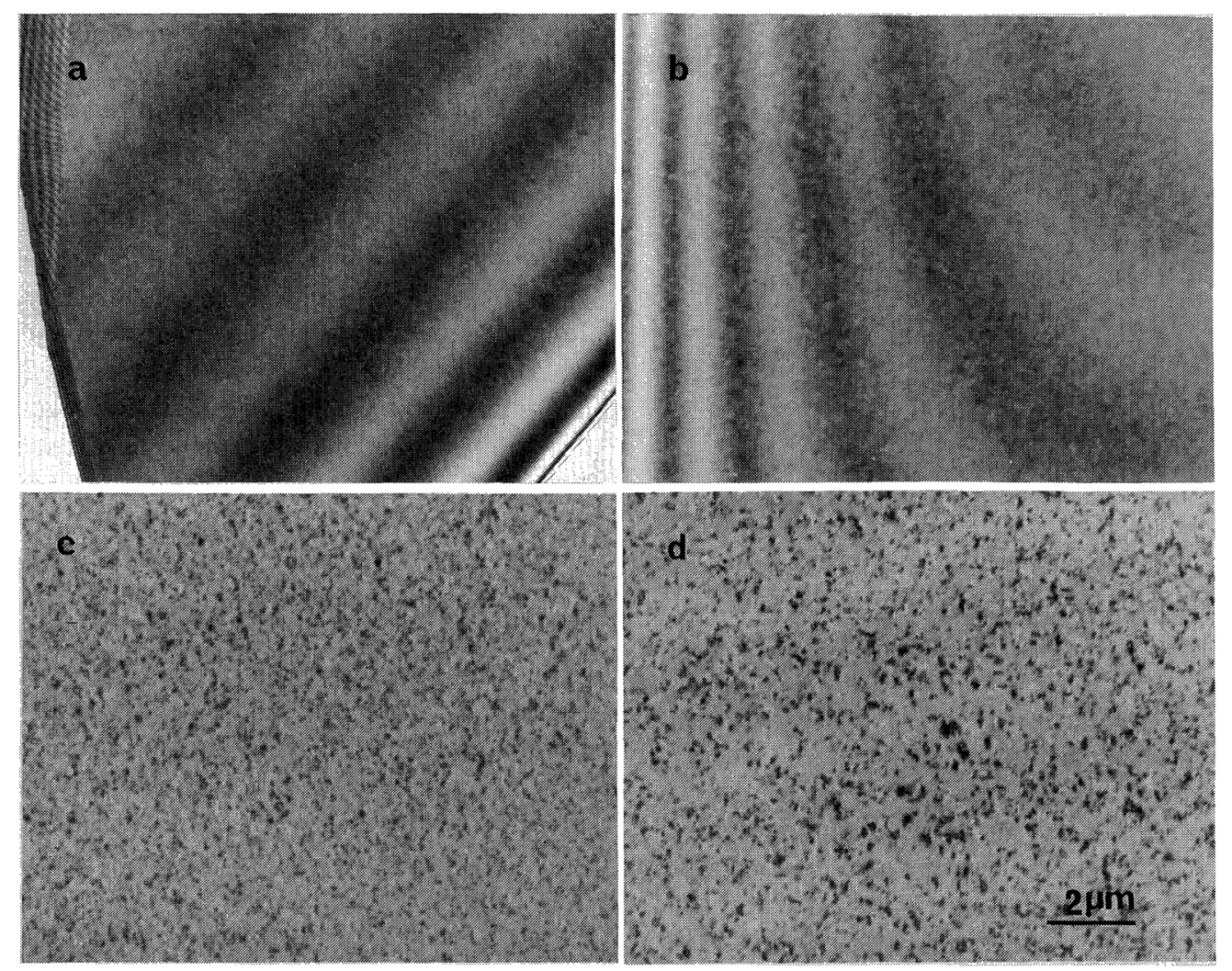

Photo. 1 Damage structure of molybdenum neutron irradiated at ambient temperature to (a) $6.3 \times 10^{21}$, (b) $1.0 \times 10^{22}$, (c) $2.4 \times 10^{23}$ and (d) $5.0 \times 10^{23} \mathrm{n} / \mathrm{m}^{2}$.

increasing the fluence to $1.0 \times 10^{22} \mathrm{n} / \mathrm{m}^{2}$. On further irradiation to 2.4 and $5.0 \times 10^{23} \mathrm{n} / \mathrm{m}^{2}$, the clusters grow larger and resolvable dislocation loops were observed in the specimens. The defect clusters in the as-irradiated molybdenum were too small to determine their nature. The small clusters which were smaller than about $3.0 \mathrm{~nm}$ in diameter showed the characteristic black-white contrast if the foils were imaged under two-beam dynamical contrast condition $\left(W_{g} \approx 0\right)$. The magnitude of the strain field estimated from Ashby and Brown's relation (19)(20) was the order of $0.2 \%$. The value shows only the order of the magnitude, since the position of the defect cluster could not be measured accurately.

Change in the yield stress at room temperature of the irradiated molybdenum with postirradiation annealing is shown in Fig. 5. The yield stress is increased by post-irradiation annealing up to $780 \mathrm{~K}$ and recovered gradually to the unirradiated level with further annealing at higher temperatures. It should be noted that the hardening is produced by the postirradiation annealing even in the specimen irradiated to $1.0 \times 10^{22} \mathrm{n} / \mathrm{m}^{2}$ which showed the radiation softening in as-irradiated condition. The relevant changes in the size distribution of the defect clusters in the specimen irradiated to $1.0 \times 10^{22}$ and $2.4 \times 10^{23} \mathrm{n} / \mathrm{m}^{2}$ are given in Fig. 6. Change in the average diameter of the defect cluster could not be observed in the specimen annealed up to $780 \mathrm{~K}$ while the number densities of the defect clusters are decreased with an increase of the annealing temperature. It should be noted that the small clusters below $3.0 \mathrm{~nm}$ in diameter did not show the characteristic black-white contrast in the post-irradiation annealed specimens. The defect clusters in the specimen annealed for $1 \mathrm{~h}$ at $973 \mathrm{~K}$ after irradiation to $5.0 \times 10^{23} \mathrm{n} / \mathrm{m}^{2}$ were analysed to be interstitial type loops 


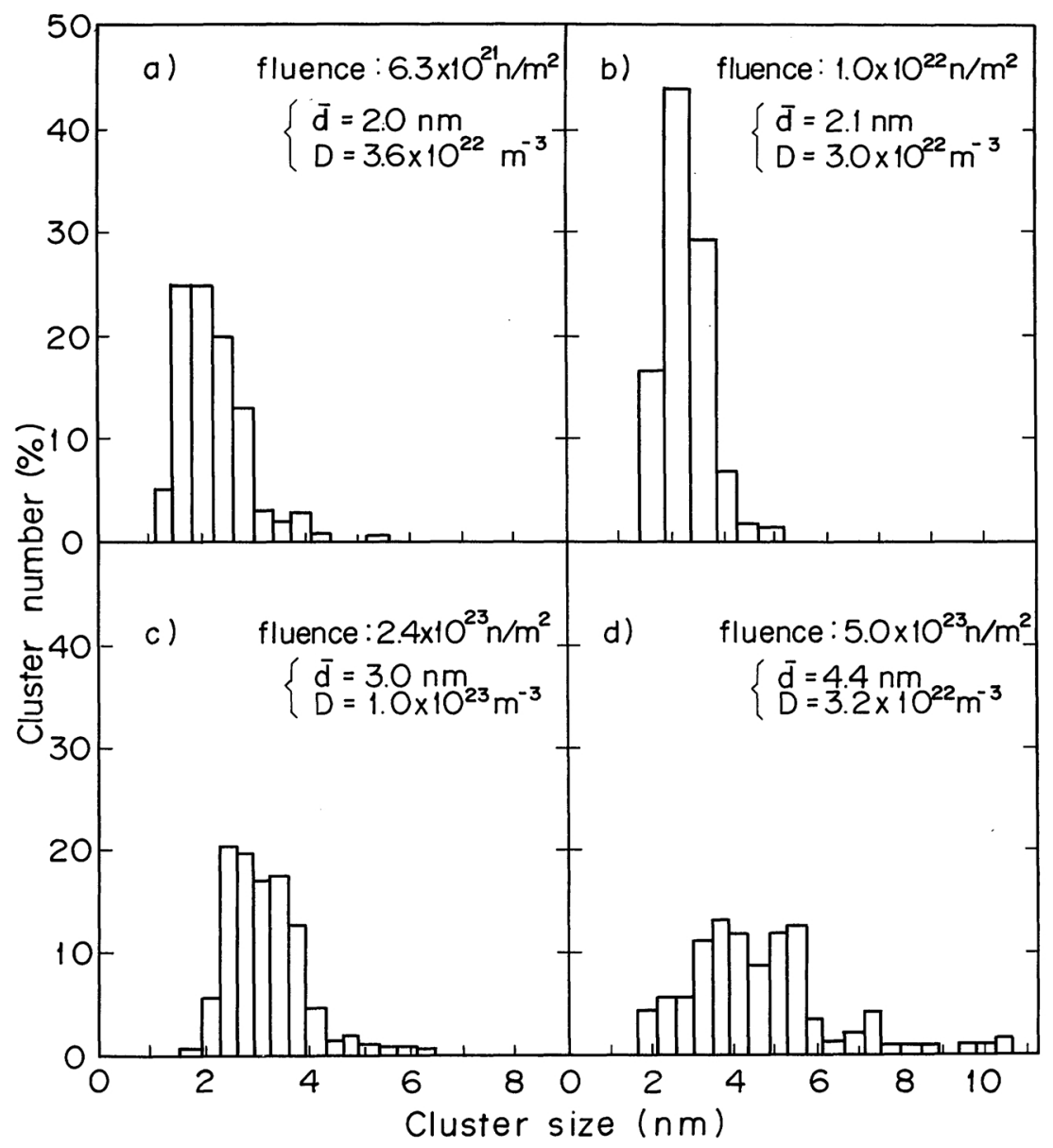

Fig. 4 Size distribution of defect cluster in molybdenum irradiated at ambient temperature.

having a Burgers vector of $\frac{1}{2}\langle 111\rangle$ and lying on the $\{111\}$ plane.

\section{Discussion}

Change in the yield stress $\sigma_{y}$ of irradiated molybdenum with the strain rate $\dot{\varepsilon}$ is well described by the equation in the form

$$
\log \sigma_{y}=\log A+K_{y} \log \dot{\varepsilon}
$$

where $A$ and $K_{y}$ are constants (Fig. 2). The strain rate dependence of the yield stress in molybdenum is not caused by the changes in dislocation structure in each irradiated specimen, but the intrinsic one as demonstrated in Fig. 7. The stress-strain curve in the figure is obtained changing the strain rate abruptly from $2.8 \times 10^{-4}$ to $2.8 \times 10^{-5} / \mathrm{s}$ and vice versa during a tensile test for the low fluence specimen. The fact that flow stress in a strain rate is not affected by the cyclic change of the strain rate indicates that the strain rate dependence of the deformation process, yielding and plastic flow, is not caused by the small change of dislocation structure but by the unit process inherent in the irradiated molybdenum. The strain rate dependence of the yield stress for unirradiated molybdenum shown in Fig. 2 consists of the two straight lines, which is thought to be attributed to the large grain size $^{(21)},(\sim 60 \mu \mathrm{m})$, of the specimen used in this investigation. Radiation damaged structure might diminish the large grain size effect.

According to the model developed by $\mathrm{Hahn}^{(22)}$, the constant $K_{y}$ in eq. (2) is inversely proportional to the dislocation-velocity para- 


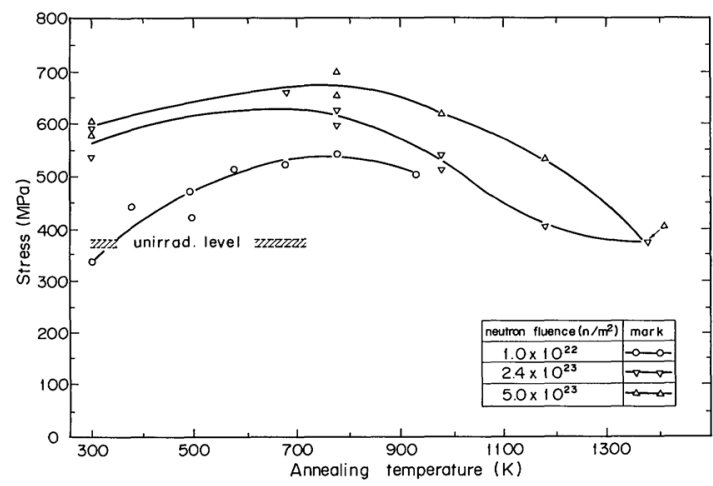

Fig. 5 Change in radiation hardening with postirradiation annealing in molybdenum irradiated at ambient temperature. meter $m$ given by

$$
v=\left(\sigma_{y} / \sigma_{0}\right)^{m}
$$

where $v$ is the dislocation velocity, and $\sigma_{0}$ is the yield stress corresponding to the unit velocity. The constant $A$ is also related to the parameter $m$ and the mobile dislocation density $\rho$ in the following form:

$$
A=\frac{\sigma_{0}}{(0.5 b \rho f)^{1 / m}}
$$

where $b$ is the Burgers vector of the dislocation and $f$ is a constant $(\approx 0.1)$. The reciprocal value of $A$ and $K_{y}$ obtained from Fig. 2 is given in Table 3 , together with mobile disloca-
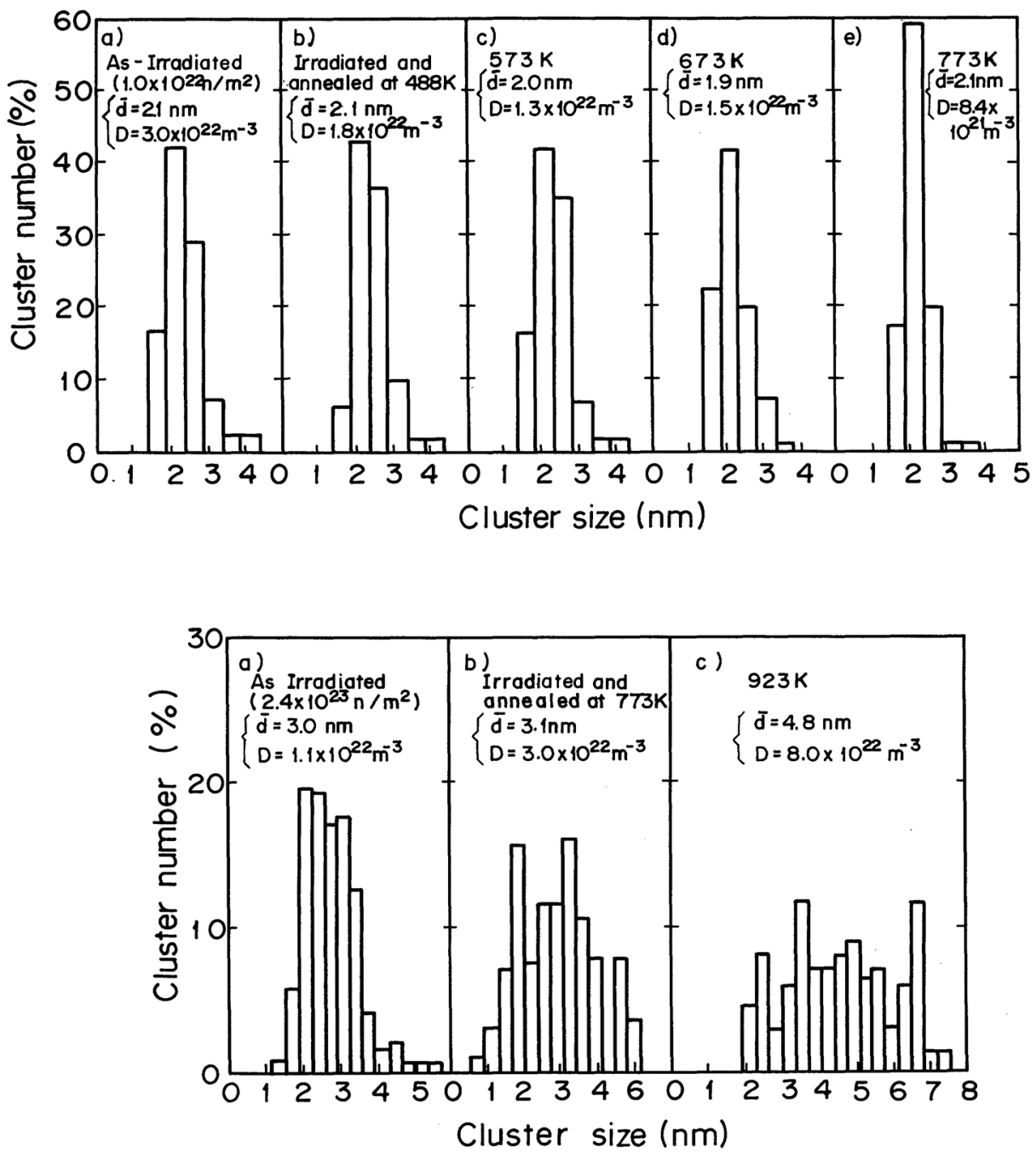

Fig. 6 Change in size distribution of defect cluster with post-irradiation annealing in molybdenum irradiated at ambient temperature. 


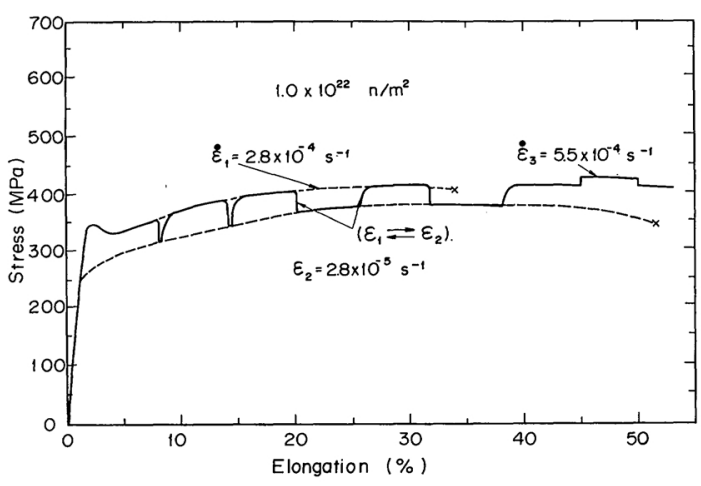

Fig. 7 Stress-strain curve for molybdenum irradiated to $1.0 \times 10^{22} \mathrm{n} / \mathrm{m}^{2}$ obtained by abrupt change of the strain rate between $2.8 \times 10^{-4}$ and $2.8 \times 10^{-5}$ in a tensile test.

Table 3 Variation of reciprocal constants $A^{-1}$ and $K_{y}^{-1}$ in eq. (2) with neutron fluence and mobile dislocation density, $\rho$.

\begin{tabular}{cccl}
\hline $\begin{array}{c}\text { Neutron fluence } \\
\left(\mathrm{n} / \mathrm{m}^{2}\right)\end{array}$ & $\begin{array}{c}A^{-1} \\
\left(\times 10^{-3}\right)\end{array}$ & $K_{y}^{-1}$ & $\begin{array}{c}\rho \\
\left(\mathrm{m} / \mathrm{m}^{3}\right)\end{array}$ \\
\hline Unirrad. & $13^{*}$ & $12^{*}$ & $1.0 \times 10^{12 * *}$ \\
$6.3 \times 10^{21}$ & 17 & 20 & $5.9 \times 10^{13}$ \\
$1.0 \times 10^{22}$ & 19 & 21 & $6.7 \times 10^{14}$ \\
$2.4 \times 10^{23}$ & 14 & 40 & $1.0 \times 10^{11}$ \\
$5.0 \times 10^{23}$ & 10 & 17 & $5.1 \times 10^{9}$ \\
\hline
\end{tabular}

* these values are obtained from the higher strain rate part.

** assumed value.

tion density estimated with eq. (4) assuming mobile dislocation in unirradiated molybdenum to be $1 \times 10^{12} / \mathrm{m}^{2}$. The table shows that the mobile dislocation density is increased by neutron irradiation up to $1.0 \times 10^{22} \mathrm{n} / \mathrm{m}^{2}$, and is decreased by further irradiation. The neutron irradiation increases the stress-velocity exponent, $m\left(=K_{y}^{-1}\right)$, and the $m$ for the irradiated specimen is rather independent upon the neutron dose. Then, the radiation softening at high strain rate in the low fluence specimen is considered to be caused by the increase in the mobile dislocation density, which reduces the constant $A$ in eq. (2).

As for the radiation softening in the low fluence specimens shown in Figs. 1, 2 and 3 and Table 2, the softening (the decrease in yield stress by neutron irradiation) is dependent on both the strain rate and the temperature of the tensile testing. The fact suggests that the radia- tion softening measured in this experiment is closely connected with the thermally activated movement of the dislocation ${ }^{(2)}$. According to Sato and $\mathrm{Meshii}^{\left({ }^{8}\right)}$, the defect clusters with strain field can behave as strain centers which assist the formation of double kink in the screw dislocation. The magnitude of the stress exerted on the dislocation located at a distance $Z$ from the defect clusters can be estimated with the misfit strength, $(4 \pi / 3) \varepsilon r^{3}$, where $\varepsilon$ is the magnitude of misfit strain and $r$ is the radius of the defect cluster. The misfit strength in this experiment is estimated to be $1.5 b^{3}$ assuming $\varepsilon=0.002, r=1.5 \mathrm{~nm}(\cong 5.6 b)$ and $b=0.27 \mathrm{~nm}$. Then, the cluster placed at $Z=6 b$ can exert torque stress equivalent to the stress induced by the strain center, for example, with $\varepsilon=0.35$, $r=2 b$ at $z=9 b$ which was shown to induce solid solution softening ${ }^{(8)}$. Thus, the torque stress exerted by the defect clusters to the screw dislocation in this experiment is large enough to make the double kinks if they are located in the proper distance from the dislocation. Reduction of the yield stress by a relatively weak strain center has been reported in Fe-Mo alloy ${ }^{(23)(24)}$. The magnitude of the misfit strength which was reported to be $\cong 2.3$ $b^{3}$ with $\varepsilon=0.012$ and $r \cong 3.7 b$ is large enough to make a solid solution softening in Fe-6.1 at $\%$ Mo. In this experiment, the average spacing of the defect clusters with strain field in the specimen irradiated to $1.0 \times 10^{22} \mathrm{n} / \mathrm{m}^{2}$ is estimated to be $500 \mathrm{~b}$, which is rather larger than the value required from the theory ${ }^{(8)}$. The result suggests that the small clusters invisible in the electron microscopy contribute to the decrease of thermal component of the yield stress in as-irradiated condition; the small clusters would have strain field. The defect clusters in the irradiated specimens are observed as black dots or small dislocation loops (Photo. 1). The black dots are composed of the two types of defect clusters; one with strain field contrast, and other without the contrast in dynamical imaging of the electron microscopy. The defect cluster smaller than $\sim 3.0 \mathrm{~nm}$ in diameter always showed the strain contrast in the as-irradiated specimens. It can, therefore, be concluded that radiation softening observed in this experiment arises from 
small defect clusters with strain field which assist the formation of a double kink.

The radiation hardening is often calculated using the following equation ${ }^{(16)}$ :

$$
\Delta \sigma_{\mu}=\frac{1}{2} \alpha \mu b\left(\sum_{i} n_{i} d_{i}\right)^{1 / 2},
$$

where $\alpha$ is a dislocation-defect interaction parameter, $\mu$ is the shear modulus, $n_{i}$ is the number of defect clusters per unit volume in a given size interval with average diameter $d_{i}$. The hardening estimated by eq. (5) is the athermal hardening; neither the temperature dependence nor the strain rate dependence is involved in the equation. The athermal component of the yield stress, the yield stress at $453 \mathrm{~K}$ in this experiment, was increased by the neutron irradiation (Fig. 3). The experimental value of the athermal hardening $\Delta \sigma_{\mu}$ is compared in Table 4 with the value calculated from defect clusters observed in electron microscopy, taking $\alpha=1, \mu=12.0 \times 10^{4} \mathrm{MPa}$ and $b=0.27$ $\mathrm{nm}$. The calculated hardenings, $\Delta \sigma_{a}, \Delta \sigma_{b}$ and $\Delta \sigma_{c}$ are for the contributions by defect clusters in all size, with diameter less than $3.0 \mathrm{~nm}$ and larger than $3.0 \mathrm{~nm}$, respectively. The table shows that the good correlation exists between the experimental value of $\Delta \sigma_{\mu}^{\prime \prime}$ and $\Delta \sigma_{c}$; the defect clusters larger than $3.0 \mathrm{~nm}$ in diameter are the obstacles which contribute to the athermal hardening in the irradiated molybdenum. It should be noted for defect clusters in as-irradiated condition that the clusters larger than $3.0 \mathrm{~nm}$ in diameter did not show the strain contrast in a two-beam dynamical contrast condition.

The hardening by post-irradiation annealing (RAH) is observed in all of the irradiated speci-

Table 4 Comparison of experimental athermal hardening $\Delta \sigma_{\mu}$ with calculated from eq. (6).

\begin{tabular}{lccrr}
\hline \hline $\begin{array}{c}\text { Neutron } \\
\text { fluence } \\
\left(\mathrm{n} / \mathrm{m}^{2}\right)\end{array}$ & $\begin{array}{c}\text { Experimental } \\
\text { value } \Delta \sigma_{\mu} \\
(\mathrm{MPa})\end{array}$ & \multicolumn{3}{c}{ Calculated value } \\
$(\mathrm{MPa})$ & $\Delta \sigma_{a}$ & $\Delta \sigma_{b}$ & $\Delta \sigma_{c}$ \\
\hline $6.3 \times 10^{21}$ & $74^{*}$ & 193 & 132 & 61 \\
$1.0 \times 10^{22}$ & 74 & 178 & 124 & 54 \\
$2.4 \times 10^{23}$ & 247 & 411 & 174 & 235 \\
$5.0 \times 10^{23}$ & 257 & 245 & 56 & 189 \\
\hline \hline
\end{tabular}

* extrapolated value.

$\Delta \sigma_{a}: 0<d_{l}<\infty, \Delta \sigma_{b}: 0<d_{i}<3.0 \mathrm{~nm}, \Delta \sigma_{c}: 3.0 \mathrm{~nm}<d_{i}$. mens (Fig. 5). The number densities of the defect cluster were slightly decreased with little change in the average diameter by annealing up to $773 \mathrm{~K}$ (Fig. 6). The defect clusters observed in the annealed specimens did not show strain contrast under two-beam dynamical condition. The facts indicate that the small defect clusters, which were observed with strain field in as-irradiated condition, resolved into the matrix during the post-irradiation annealing. In Table 5 the RAH produced by $773 \mathrm{~K}$ annealing is compared with the value calculated by eq. (5) taking into account the contributions of all defect clusters observed in the electron microscopy. The calculated values are fairly in agreement with the observed one. It is reasonable in the calculation that all defect clusters observed in the electron microscopy account for the RAH, since even the smallest cluster has no strain field contrast in two-beam dynamical condition. Thus, the radiation hardening or increase in the athermal component of the yield stress is considered to be attributable to defect clusters without strain field, although defect clusters invisible in the electron microscopy would contribute to the RAH.

\section{Conclusion}

The following conclusions can be drawn from the result of this investigation.

(1) The radiation softening in the molybdenum irradiated to $6.3 \times 10^{21}$ and $1.0 \times 10^{22}$ $\mathrm{n} / \mathrm{m}^{2}$ (low fluence specimens) and the radiation hardening in the specimen irradiated to $2.4 \times$ $10^{23}$ and $5.0 \times 10^{23} \mathrm{n} / \mathrm{m}^{2}$ was observed in tensile testing at room temperature with a strain rate of $2.8 \times 10^{-4} / \mathrm{s}$.

(2) Radiation softening and hardening in

Table 5 Comparison of observed RAH with the calculated value $\Delta \sigma_{d}$.

\begin{tabular}{ccc}
\hline $\begin{array}{c}\text { Neutron fluence } \\
\left(\mathrm{n} / \mathrm{m}^{2}\right)\end{array}$ & $\begin{array}{c}\mathrm{RAH} * \\
(\mathrm{MPa})\end{array}$ & $\begin{array}{c}\Delta \sigma_{d} \text { calculated } \\
\text { value }(\mathrm{MPa})\end{array}$ \\
\hline $1.0 \times 10^{22}$ & 163 & 100 \\
$2.4 \times 10^{23}$ & 236 & 163 \\
$5.0 \times 10^{23}$ & 300 & 192 \\
\hline
\end{tabular}

* $\mathrm{RAH}=\sigma_{\mathrm{y}}(773 \mathrm{~K}$ anneal $)-\sigma_{\mathrm{y}}$ (unirrad. $)$. 
the as-irradiated molybdenum is dependent on the strain rate and test temperature. The radiation softening in the low fluence specimens is resulted from the fact that the decrement of the thermal component of the yield stress is larger than the increment of the athermal component.

(3) The decrease in the thermal component of the yield stress is attributable to the defect clusters with strain field, which assist the formation of double kink in the screw dislocation.

(4) The increase in the athermal component with neutron irradiation and also postirradiation annealing up to $773 \mathrm{~K}$ is attributable to the defect clusters without strain field.

\section{Acknowledgements}

The authors wish to express their thanks to Drs. R. Nagasaki and J. Shimokawa for their interest in this work.

\section{REFERENCES}

(1) F. W. Wiffen: Defects and Defect Clusters in B.C.C. Metals and their Alloys, NBS, (1973), p. 176.

(2) For example, H. Conrad: Mechanical Bevavior of Metals at Elevated Temperatures, McGrawHill, (1961), p. 185.

(3) R. J. Arsenault: Acta Met., 15 (1967), 1853.

(4) D. F. Hasson, Y. Huang, E. Pink and R. J. Arsenault: Met. Trans., 5 (1974), 371.

(5) P. Groh, F. Vanoni and P. Moser: Defects and Defect Clusters in B.C.C. Metals and their Alloys, NBS, (1973), p. 19.
(6) K. Kitajima, H. Abe, S. Takamura and S. Okuda: Fundamental Aspects of Radiation Damage in Metals, US ERDA, (1975), p. 977.

(7) A. Sato, T. Mifune and M. Meshii: Phys. Status Solidi (a), 18 (1973), 699.

(8) A. Sato and M. Meshii: Acta Met., 21 (1973), 753.

(9) G. P. Seidel: Phys. Status Solidi, 25 (1968), 175.

(10) K. Kitajima: Proc. Int. Conf. on Strength of Metals and Alloys, Supplement to Trans. JIM, Vol. 9 (1968), p. 182.

(11) M. S. Wechsler, R. P. Tucker and R. Bode: Acta Met., 17 (1969), 541.

(12) R. J. Arsenault and E. Pink: Mater. Sci. and Eng., 8 (1971), 141.

(13) F. A. Smidt, Jr.: J. Appl. Phys., 36 (1965), 2317.

(14) S. B. McRickard: Acta Met., 16 (1968), 969.

(15) M. Boček, H. Böhn and W. Schneider: J. Nucl. Mater., 40 (1970), 249.

(16) B. A. Loomis and S. B. Gerber: Acta Met., 21 (1973), 165.

(17) K. Shiraishi, K. Fukaya and Y. Katano: J. Nucl. Mater., 54 (1974), 275.

(18) R. Bajaj and M. S. Wechsler: Fundamental Aspects of Radiation Damage in Metals, US ERDA, (1975), p. 1010.

(19) M. F. Ashby and L. M. Brown: Phil. Mag., 8 (1963), 1083.

(20) M. F. Ashby and L. M. Brown: Phil. Mag., 8 (1963), 1649.

(21) R. N. Orava: Trans. Met. Soc. AIME, 230 (1964), 1614.

(22) G. T. Hahn: Acta Met., 10 (1962), 727.

(23) A. Urakami, H. L. Marcus, M. Meshii and M. E. Fine: Trans. ASM, 60 (1967), 344.

(24) T. Sakuma and S. Karashima: Strength of Metals and Alloys, 1 ASM (1970), p. 88. 